UDC 34.06

LBC 67.75

\title{
OFFICIAL PHONODOCUMENTS AS TECHNOTRONIC SOURCES IN THE SYSTEM OF SOCIAL COMMUNICATION
}

\author{
Oleg V. Sineoky \\ Zaporozhsky National University, Zaporozhe, Ukraine
}

\begin{abstract}
Introduction: the concept of phonodocumental communication is presented in the form of fragmented elements, seamlessly brought together and integrated into a balanced system. The typology of phonodocuments is based on the novel traits - the types of sound-recording media, the features of the recorded audio content and the specifics of the service functions. The research methodology is based on the meta-theory of social communication (noocommunology). There is undertaken a significant extension of the research field due to the deep systematization of the block of non-musical phonodocuments - there are distinguished official phonodocuments as a special cluster of the communication space. There are clarified the nature and purpose of phonodocuments of this type. There are formulated the basic formation laws and the classification principles of official phonodocuments. There are separately considered the peculiarities of organizing the use of phonodocuments by lawyers (records, archives).

Key words: sound recording, sound-recording medium, official phonodocuments, service document, technotronic sources, social communication, advocatory phonodocuments.
\end{abstract}

УДК 34.06

ББК 67.75

\section{СЛУЖЕБНЫЕ ФОНОДОКУМЕНТЫ КАК ТЕХНОТРОННЫЕ ИСТОЧНИКИ В СИСТЕМЕ СОЦИАЛЬНЫХ КОММУНИКАЦИЙ}

\author{
Олег Владимирович Синеокий
}

Запорожский национальный университет, г. Запорожье, Украина

\begin{abstract}
Введение: концепция фонодокументной коммуникации представлена в виде разобщенных элементов, органично собранных воедино и интегрированных в сбалансированную систему. Типология фонодокументов базируется на новых признаках - видах звуконосителей, особенностях зафиксированного аудиоконтента и специфике сервисных функций. Методология исследования основана на метатеории социальной коммуникации (ноокоммунологии). Предпринято значительное расширение исследовательского поля за счет углубленной систематизации блока немузыкальных фонодокументов - в качестве особого кластера коммуникационного пространства выделены служебные фонодокументы. Выяснены сущность и назначение фонодокументов данного типа. Сформулированы основные закономерности формирования и принципы классификации служебных фонодокументов. Отдельно рассмотрены особенности организации использования фонодокументов адвокатами (досье, архивы).

Ключевые слова: звукозапись, звуконоситель, служебный фонодокумент, сервисный документ, технотронные источники, социальные коммуникации, адвокатские фонодокументы.
\end{abstract}

\section{Введение}

В условиях активного формирования качественно нового уровня социоинформационной среды со стремительным возрастанием уровня потоков звуковых сообщений актуаль- ность представленного исследования обусловлена отсутствием фундаментальных исследований, посвященных проблематике циркуляции служебных фонодокументов в коммуникационном пространстве в качестве технотронных источников. 
Хотя фонодокументы остаются малоизученными самостоятельными источниками, истоки их изучения в качестве нового информационно-правового явления ведут к концу 1940-х годов. К концу 1950-х гг. фонодокументы выделены в особую группу, рассматриваемую в комплексе с кино- и фотодокументами. Существенным вкладом в разработку этой проблематики стали диссертации О. Седовой, И. Полотовской, Т. Надольской, Л. Кобельковой, Л. Розановой, И. Миронычевой, Н. Грюнберга, В. Устинова, А. Якупова, Л. Тупчиенко-Кадыровой, защищенные в период с 1973 по 2013 год.

Работы украинских исследователей (среди которых следует в первую очередь отметить Н. Кушнаренко и Г. Швецову-Водку), созданные и опубликованные на протяжении последних трех десятилетий, пользуются - по словам профессора кафедры аудиовизуальных документов и архивов Московского историкоархивного института Г. Ланского - значительным признанием не только на территории Украины, но и далеко за ее пределами в рамках других государств постсоветского региона. В них достаточно четко проявился информационный подход к изучению различных видов документов, направленный, прежде всего, на выявление роли различных типов (и в их рамках видов) информационных ресурсов в сфере формирования социальной памяти и развития массовых коммуникаций [3, с. 3]. Представленная работа развивает применение данного исследовательского подхода в отношении фонодокументов, которые на данный момент остаются на периферии исследовательского интереса даже по сравнению с другими видами технотронных документов - изобразительными, аудиовизуальными, электронными информационными ресурсами, различными видами технической документации, что позволяет в определенной мере преодолеть существующие, в том числе - и в современной учебной литературе, разночтения [5].

Предмет публикации - содержание, типология, сервисные функции, правовые особенности функционирования служебных фонодокументов как источников зафиксированной аудиоинформации разных видов.

Цель публикации - в рамках развития целостной концепции генезиса и функциониро- вания фонодокументной коммуникации вычленить служебные фонодокументы как особый сектор специфических сервисных средств и уточнить классификацию информационных аудиоисточников данного типа.

Методологическую основу публикации составили труды отечественных и зарубежных ученых (Л. Афанасьева, В. Бездрабко, С. Безклубенко, В. Бондарь, Г. Боряк, Г. Двоеносова, Г. Залаев, С. Зозуля, Т. Емельянова, Л. Кобелькова, В. Коляда, С. Кулешов, Н. Кушнаренко, В. Магидов, К. Новохатский, Т. Надольская, Ю. Палеха, М. Палиенко, А. Сокова, Е. Старостин, Ю. Столяров, А. Филиппов, Х. Хащина, И. Хорхордина, Г. Швецова-Водка и др.), оказавшие влияние на разработку обозначенной проблемы.

\section{Сущность и функции служебных фонодокументов}

Тезис о комплексном характере служебного права получил подробную разработку в основном в трудах И. Дякиной. Согласно ее мнению сегодня четко определился круг правовых источников, которые имеют правовую природу непосредственно правовых актов только служебного свойства, однако специального характера [2]. Не вступая в данной публикации в полемику об обоснованности и целесообразности выделения служебного права в самостоятельную отрасль права либо о преждевременности его существования как самостоятельной комплексной отрасли (О. Иоффе, Е. Киримова и ряд других ученых принципиально отрицает существование комплексных отраслей права), все же следут заметить, что предмет комплексной отрасли целостен, представляя собой определенную социальную систему (В. Протасов), одним из базисных элементов которой являются документы, выполняющие правовую функцию (правовые акты органов власти и управления, акты судебных, прокурорских, нотариальных учреждений; акты, созданные в других учреждениях, организациях, предприятиях, фирмах, которые влекут за собой юридические последствия; международные, межгосударственные и другие договоры). Кроме этого, документы составляют основу информационной среды государственного и муниципального органа 
либо учреждения, предприятия или организации. Содержащаяся в них информация будет обладать юридической силой и может быть использована в профессиональной деятельности только при соблюдении ряда обязательных требований, предъявляемых к составлению служебных и иных документов, включенных в документооборот. Подавляющая часть официальных документов создается в сфере управления.

Существует множество дефиниций документа. В нашем случае под термином «документ» понимается материальный объект с зафиксированной на нем информацией, оформленный согласно установленным правилам документирования с реквизитами, позволяющими идентифицировать данные.

Особым видом документов являются фонодокументы, которым присущи весьма специальные свойства. Анализ нормативных источников показал отсутствие дефиниции такого объекта, как «фонодокумент» с нормативным закреплением его основных видов, что создает сложности для его вовлечения в научный и практический оборот. Кино-, теле-, видео- и фотодокументы, диафильмы и диапозитивы, микрографические и голографические документы, электронные текстовые документы, аудиозапись и т. п., созданные и воспринимаемые с помощью технических средств, относят к технотронным документам, однако корреляция «технотронный/электронный» остается дискуссионной. Термин «фонодокумент» предлагается использовать как обобщающее понятие для всех функционирующих в коммуникационном пространстве видов аудиовизуальных документов, содержащих записи звуковых сообщений и дополненных разнородными визуальными элементами.

Фонографическое документоведение, изучающее закономерности фонодокументной информационной деятельности, представлено в виде системы научного знания о фонодокументах различных видов и сопряженных с ними объектах. Продолжение данной базисной позиции делает очевидным наличие высокого дуалистического потенциала - сервисно-вспомогательной и официально-должностной функций применения такого важного вида фонодокументов, как служебные.
Сформулируем основные функции фонодокумента: 1) временное и/или длительное хранение звуковых записей на носителях определенных типоформатов; 2) трансляция предварительно зафиксированной звуковой информации при помощи специальных технических устройств на индивидуальном, групповом и массовом уровнях.

Расширительное толкование термина «служебный фонодокумент» включает четыре плоскости значений: 1) фонодокумент, относящийся к исполнению служебных обязанностей, то есть являющийся объектом (предметом) или средством профессиональной деятельности; 2) фонодокумент, предназначенный для пользования строго определенным кругом субъектов (работников); 3) фонодокумент, являющийся дополнением (вспомогательный, второстепенный) к иному главному документу; 4) фонодокумент, выполняющий те либо иные сервисные функции информационного и/или технологического характера. Таким образом, к массиву служебных фонодокументов относятся не только содержащие в зафиксированном виде какую-либо служебную информацию.

В широком смысле к служебным фонодокументам можно отнести все архивные, библиотечные и юридические фонодокументы, телефонограммы, учебно-методические, звукозаписи селекторных совещаний и многие другие аудиозаписи. В узком смысле это зафиксированная на носителе дополнительная (вспомогательная) информация, уточняющая базовый документ (причем не обязательно звуковой) или состояние документооборота; информационно-справочные, чистящие и проверочные диски, звуковые приложения (от бонус-треков до аудиогидов), аудиоприложения, рабочие фонограммы, промо-записи и т. п., то есть такие, которые при использовании в автономном режиме теряют свое изначальное социальное назначение (цель) и заложенный создателями в них смысл. Особо выделяются фонодокументы с ограниченным доступом (зашифрованные, звуковые криптограммы и др.).

Заметим, что на законодательном уровне в Украине не закреплен термин «фонодокументы с ограниченным доступом», который употребляется в смысле документальных 
сведений, зафиксированных в звуковой форме, для возможности ознакомления с содержанием которых и порядка пользования государством или владельцем установлен специальный правовой режим. Звуковые данные с ограниченным доступом имеют особую социальную ценность в силу их недоступности и потенциальной неизвестности третьим лицам.

Как известно, действует презумпция открытости информации. Правовой режим информации является характеристикой информации как объекта правоотношений, вводится нормативным правовым актом и призван согласовать публичную потребность в свободе циркуляции информации и право личности на закрытую информацию и сохранение тайн. Режим открытой информации является общим правовым режимом информации, в том числе звуковой. Установление специального порядка реализации доступа к отдельным видам звуковой информации не означает его ограничения, в том числе в тех случаях, когда этой информацией владеют коммерческие структуры, однако это не отменяет действие общего правового режима информации [6]. В случаях, когда аудийная информация становится особым объектом гражданских прав, такие сведения должны иметь коммерческую ценность. Прежде всего это характерно для музыкальных звукозаписей (но и не только для них). Особо следует отметить, что классификация информации по порядку (режиму) доступа, несмотря на множество нормативно-правовых актов в информационной сфере, является весьма сложной и запутанной, оставляя ряд нерешенных проблемных вопросов.

Определение ценности информации - это субъективный процесс, и в большинстве случаев не существует объективных критериев по поводу определения ценности конкретных видов фонодокументов. Общим во всех определениях информационных правоотношений является то, что они возникают, изменяются и прекращаются в связи с информацией - в нашем случае речь идет исключительно о звуковой информации. Ключевым свойством звуковой информации (равно как и любой иной) является пригодность для фиксирования. Это означает, что аудиоинформация может существовать только в зафиксированном состоянии. Носителями информации рассматривае- мого вида являются данные, представляющие собой зарегистрированные сигналы, - при этом физический метод их регистрации может быть любым. Свойства аудиальной информации достаточно тесно связаны со свойствами ее носителей.

Свойства служебных фонодокументов направлены не только на сохранение строго определенного звукового сообщения неизменным в пространстве и времени (безусловный сервис), но и на осуществление настроечных функций звуковоспроизводящих комплексов с целью создания и поддержки эталонного звучания (бигеминальный сервис).

\section{Типология служебных фонодокументов}

Как известно, одним из важных источников информации являются документы различных видов и классов. Распределение документов по группам (видам) на основе признаков содержания, формы составления и др. с целью организации и повышения эффективности работы с ними естественно составляет содержание классификации документов.

Для построения общей типологии служебных фонодокументов носители всех типов предложено расчленить на группы: три основные (грампластинки; магнитная лента на кассетах, катушках, картриджах; оптические диски) и одну дополнительную (портативные запоминающие устройства-накопители).

Существует взаимообусловленность базовых категорий «типоразмер» (вид носителя с указанием объема аудиоинформации и основных параметров для воспроизведения - например, шеллаковая патефонная пластинка на 78 об/мин и т. п.) и «типоформат» (совокупность параметров с указанием конфигурации базовых элементов - например, кассетный макси-сингл, два альбома на одном компактдиске и т. п.) носителя с записанным звуком.

Исходя из объема зафиксированной звуковой информации, можно классифицировать служебные фонодокументы на: 1) малоформатные (до 15 мин); 2) среднеформатные (от 15 до 30 мин); 3) крупноформатные (от 30 до 100 мин); 4) мегаформатные, мультиформатные, смешанные (свыше 100 мин).

Отдельно предлагается выделить блок неформатных фонодокументов (в том числе 
несистемные выпуски): сувенирные (Shaped Disc, Colour Vinyl, Multi-Sided Records, Picture Disc, Floppy-ROM); «пластинки-опечатки» (Flop, Mispressed Records, Misprint); семейство так называемых «карликовых МФД» («Гном» и т. п.); разговорные (Show \& Tell, Talking Books).

В целом фонодокументы предлагается классифицировать на общие и специальные. Весь массив служебных фонодокументов входит во вторую группу и частично - в первую. Фонодокументы данного типа могут быть неразделимыми и раздельными, то есть состоящими из отдельных частей в виде дорожек, композиционно между собой не связанных, либо объединенными в единую цельную конструкцию на основании второстепенных признаков.

Обратим внимание на то, что фонодокументы могут быть оригинальными и копиями (в данном случае речь идет о перезаписывании фонограмм), а также студийными и нестудийными, профессиональными и любительскими, легальными (лицензионными) и контрафактными (подделки). Основываясь на внутренней структуре служебного фонодокумента как на информационной системе, такие документы могут быть сгруппированы на «простые» (аудиозапись подается на одном или нескольких разных носителях) и «сложные» (идентичные полностью либо частично записи представлены в едином комплекте на разнородных носителях - например, на грампластинке, компакт-диске и магнитофонной кассете в различных комбинациях компонентов).

Гибридная популяция фонодокументов представлена как шесть базовых классов, структурированных в единый коммуникационный периметр: пластинки (патефонные, граммофонные, эбонитовые, шеллаковые, виниловые плоские диски различных типоформатов...), магнитная лента на бобинах/катушках (аналоговые и цифровые компакт-кассеты, 8-трековые картриджи, DAT-кассеты...), магнитные непленочные накопители (флоппи и дискеты на гибких магнитных дисках, магнитооптические диски в картриджах, минидиски...), оптические диски (audio-CD, CDRW, DVD-audio, SACD, CDDA, SHM-CD, BluSpec CD, Blu-Ray...), накопители нового поколения (ленточные стримеры, съемные твер- дотельные картриджи, внешние жесткие диски, флешки...), облачные хранилища данных без носителей (Spotify, FMA, iTunes, Apple Music, iCloud Music Library, Pledge Music...).

Основываясь на базовых признаках, предлагаем расширить типизацию фонодокументов, дополнительно выделив такой показатель, как правовой режим аудиоинформации - свободный доступ/ограниченный доступ. К первой категории относятся открытые и общедоступные фонодокументы, ко второй фонодокументы с ограниченным доступом и секретные фонодокументы. В данном контексте немаловажным является нормативно закрепленное разграничение информации с ограниченным доступом на конфиденциальную, тайную и служебную [1]. При этом каждый из этих видов предполагает возможность дальнейшего дробления на подвиды по различным признакам.

В качестве информационно-правовой основы секретных фонодокументов предлагаем положить обновленную классификацию тайн: 1) фонодокументы, содержашие объективную тайну (служебно-государственная тайна); 2) фонодокументы, содержащие субъективную тайну (персонально-личностная тайна); 3) фонодокументы, содержащие вариативную тайну (профессионально-корпоративная тайна). К служебным фонодокументам относятся первая и третья группы, отношение же второй группы к исследуемой категории требует дополнительной теоретической проработки в частности, научной аргументации в ответе на вопрос о правовом режиме личных фонодокументов вспомогательного и незавершенного характера.

Цифровые фонограммы, обращающиеся в Интернете, преждевременно относить к особому классу фонодокументов. Считаем, что подобные сетевые преобразования фонодокументных потоков являются отдельными стадиями жизненного цикла.

Среди служебных немузыкальных фонодокументов выделяются: 1) исторические; 2) учебные; 3) политические; 4) событийные фонозаписи, отражающие звуковую сторону каких-либо событий: митингов, совещаний и т. д. в момент их свершения); 5) фоноинтервью и фономемуары (по содержанию воспоминаний приближающиеся к письменным ис- 
точникам); 6) по чрезвычайным происшествиям (так называемые «черные ящики» и др.); 7) юридические; 8) журналистские; 9) научноисследовательские.

Подчеркнем, что в результате совокупного применения различных подходов классификации один и тот же фонодокумент может быть отнесен к нескольким категориям одновременно (например, опубликованный, первичный, непериодический, оригинальный, зарубежный, служебный и т. п.). Примеры эффективности функционирования отдельных кластеров служебных фонодокументов в исторической, музыкальной, юридической, медицинской, военной, учебной, научно-технической, транспортной и других сферах свидетельствуют о перспективности применения такой модели. Следует подчеркнуть, что в отдельных случаях (причем нередко) профильные кластеры служебных фонодокументов могут пересекаться, образуя «гибридные зоны».

\section{Адвокатские фонодокументы}

Кратко укажем результаты по выделению в группе юридических технотронных источников сектора адвокатских фонодокументов. Очевидно, что они образуют звуковой сектор общего массива правовых документов.

Центральное место в юридической практике отводится фактам как источникам информации, которые имеют различные способы фиксации. Законом разрешено фиксировать с помощью технических средств информацию, содержащуюся в материалах дела, по которому адвокат оказывает юридическую помощь, соблюдая при этом государственную и иную охраняемую законом тайну. Это дает ему возможность беспрепятственно с помощью собственной техники копировать всю необходимую информацию из юридического дела, которое он ведет. Как известно, действует презумпция открытости информации. Тем не менее предоставление адвокатам-защитникам реального права собирать и представлять доказательства до сих пор вызывает острые дискуссии. При этом высказываются диаметрально противоположные точки зрения. Адвокатская криминалистика служит не только для нейтрализации доказательств, полученных с помощью классической криминалистики (Р. Мельничен- ко), но и позволяет в интересах клиента «действовать на опережение». Основываясь на нашем десятилетнем опыте написания учебных пособий по адвокатуре для вузов Украины [4], предлагается считать адвокатскую криминалистику быстрым, действенным и эффективным способом защиты интересов граждан и юридических лиц, направленным на получение с использованием технических средств благоприятных для клиента доказательств. В рассматриваемом случае такими техническими средствами выступают (чаще всего малогабаритные) звукозаписывающие устройства.

На вопрос «может ли адвокат создавать документы» положительный ответ очевиден. Оригиналы документов и их копии являются основой для формирования адвокатского досье (внутреннее использование), а также направляются в виде ходатайств, адвокатских запросов, жалоб и т. п. в правоохранительные органы, государственные учреждения и другие организации всех форм собственности (внешнее использование). Однако остается нерешенной проблема допустимости непроцессуальной фиксации адвокатом рассказов очевидцев и других звуковых сообщений, имеющих уникальный характер с последующей легализацией в установленном порядке. В целом же адвокатские фонодокументы, содержащие в зафиксированном виде профессиональную информацию, предлагается относить к массиву служебных и сервисных фонодокументов. Можно построить логическую цепочку: «адвокатские фонодокументы» $\rightarrow$ «юридические фонодокументы» $\rightarrow$ «служебные фонодокументы». Весь массив адвокатских фонодокументов предлагается разграничить на две большие группы - рабочие (размещаются в адвокатском досье для оперативного использования в работе по определенному делу) и архивные (хранятся в архиве адвоката после завершения работы над конкретным делом). Следует особо разработать и внедрить технологические меры по обеспечению безопасности данной конфиденциальной информации.

В современных информационных условиях проблема бездокументарных звукозаписей выходит на новый технологический уровень: тайные «пленки», «шпионские часы» и другие 
комбинированные устройства скрытой звукозаписи с зафиксированной речевой информацией компрометирующего характера и т. п. В этой связи предлагается выделить фонодокументы с ограниченным доступом и секретные фонодокументы. Значительное влияние на устойчивость всей системы оказывает проблема фальсификации служебных фонодокументов.

Результаты. Исследование проделано в рамках целостной концепции фонодокументной коммуникации. Произведена классификация фонодокументов всех типов с выделением служебных фонодокументов как технотронных источников особого типа. Теоретически доказана и практически проверена обоснованность гипотезы цикличности развития фонодокументных коммуникаций. Тестирование происходило на основе реконструкции собранного эмпирического материала и расчетов в различных взаимосвязанных плоскостях. Отдельно описаны свойства адвокатских фонодокументов.

Заключение. Представленный вариант по большому счету не противоречит принятым классификациям. Впрочем, схема типологической классификации фонодокументов не является завершенной, находится в процессе развития и постепенно совершенствуется.

\section{СПИСОК ЛИТЕРАТУРЫ}

1. Баскаков, В. Ю. Адміністративно-правовий режим інформації з обмеженим доступом : автореф. дис. ... канд. юрид. наук / Баскаков Володимир Юрійович. - Киев, 2012. - 24 с.

2. Дякина, И. А. Служебное право как комплексная отрасль права : автореф. дис. ... Д-ра юрид. наук / Дякина Ирина Александровна. - Ростов н/Д, 2007. $-38 \mathrm{c}$.

3. Ланской, Г. Н. Вступительное слово / Г. Н. Ланской // Синеокий, О. В. Фонодокумент в мировом коммуникационном пространстве: эволюция, современное состояние, направления трансформаций: специальный международный научно-реферативный выпуск / О. В. Синеокий. - Запорожье : Статус, 2017.

4. Синеокий, О. В. Адвокатура как институт правовой помощи и защиты: новый курс адвокатского права и адвокатской криминалистики
/ О. В. Синеокий. - 2-е изд., испр. и доп. - Харьков : Право, 2012. -520 с.

5. Синеокий, О. В. Социокоммуникационная характеристика служебных и сервисных фонодокументов: сущность, типология, функции, правовой режим / О. В. Синеокий // NB: Административное право и практика администрирования. - 2017. № 4. - C. $50-72$.

6. Терещенко, Л. К. Правовой режим информации : автореф. дис. ... д-ра юрид. наук / Терещенко Людмила Константиновна ; Ин-т законодательства и сравнительного правоведения. - М., 2011. $-54 \mathrm{c}$.

\section{REFERENCES}

1. Baskakov V.Yu. Administrativno-pravovii rezhim nformats z obmezhenim dostupom: avtoref. dis. ... kand. yurid. nauk [The Administrative and Legal Regime of Information with Restricted Access. Cand. jurid. sci. abs. diss.]. Kyiv, 2012. 24 p.

2. Dyakina I.A. Sluzhebnoe pravo kak kompleksnaya otrasl prava: avtoref. dis. d-ra iurid. nauk [Service Law as a Complex Branch of Law. Cand. jurid. sci. abs. diss.]. Rostov-on-Don, 2007. 38 p.

3. Lanskoy G.N. Vstupitelnoe slovo. Synieokiy O.V. Fonodokument $v$ mirovom kommunikatsionnom prostranstve: evolyutsiya, sovremennoe sostoyanie, napravleniya transformatsiy: spetsialnyy mezhdunarodnyy nauchno-referativnyy vypusk [Introduction to the Book: Sineokiy O.V. Phonodocument in the World Communication Space: Evolution, Current State, Directions of Transformations: a Special International Scientific and Abstract Issue]. Zaporozhye, Status Publ., 2017.

4. Sineokiy O.V. Advokatura kak institut pravovoy pomoshchi i zashchity: novyy kurs advokatskogo prava $i$ advokatskoy kriminalistiki [Advocacy as an Institution of Legal Assistance and Protection: a New Course of Law and Lawyer Forensic Science]. Kharkov, Pravo Publ., 2012. 520 p.

5. Sineokiy O.V. Sotsiokommunikatsionnaya kharakteristika sluzhebnykh i servisnykh fonodokumentov: sushchnost, tipologiya, funktsii, pravovoy rezhim [Sociocommunication Characteristics of Service and Service Phonodocuments: Essence, Typology, Functions, Legal Regime)]. NB: Administrativnoe pravo i praktika administrirovaniya, 2017, no. 4, pp. 50-72.

6. Tereshchenko L.K. Pravovoy rezhim informatsii: avtoref. dis. ... d-ra yurid. nauk [Legal Information Regime. Dr. jurid. sci. abs. diss.]. Moscow, $2011.54 \mathrm{p}$. 


\section{Information about the Author}

Oleg V. Sineoky, Doctor of Sciences in Social Communication, Candidate of Juridical Sciences, Professor, Department of the Theory of Communication, Advertising, Public Relations and Media Law, Associate Professor (Department of Criminal Law and Justice), Zaporozhsky National University, Zhukovsky St., 66, 69600 Zaporozhe, Ukraine, olegwsineoky@rambler.ru.

\section{Информация об авторе}

Олег Владимирович Синеокий, доктор наук по социальным коммуникациям, кандидат юридических наук, профессор кафедры теории коммуникации, рекламы, связей с общественностью и медиаправа, доцент (по кафедре уголовного права и правосудия), Запорожский национальный университет, ул. Жуковского, 66, 69600 г. Запорожье, Украина, olegwsineoky@rambler.ru. 